\title{
Moeda, crédito e reforma do Estado imperial português: os escritos de D. Rodrigo de Souza Coutinho, 1783-1800
}

Money, Credit and Reform in the Portuguese Imperial State: the writings of D. Rodrigo de Souza Coutinho, 1783-1800

Bruno Aidar (1)

(1) Universidade Federal de Alfenas

\section{Abstract}

The article aims to analyse some ideas about money and credit in the writings of the Portuguese statesman D. Rodrigo de Souza Coutinho (1755-1812) in the end of the 18th century, giving emphasis to the Brazilian dimension and to the appropriation and transformation of Smithian ideas. The text presents the reflections produced when Souza Coutinho was ambassador in Turin and after State Secretary of the Overseas Domains and Navy Affairs. It is also discussed the projects to issue paper money and the plans to create credit institutions to promote the colonial economy.

\section{Keywords}

Rodrigo de Souza Coutinho; money; credit; portuguese empire.

JEL Codes B12. B31. N16.

\section{Resumo}

$O$ artigo procura analisar as ideias sobre a moeda e crédito nos escritos do estadista português $D$. Rodrigo de Souza Coutinho (1755-1812) do final do século XVIII, destacando a dimensão do Brasil $e$ as apropriações e transformações das leituras de Adam Smith. O texto apresenta as reflexões sobre esses temas realizadas por Souza Coutinho como embaixador em Turim e posteriormente como Secretário de Estado dos Negócios da Marinha e Dominios Ultramarinos. Também são discutidos os projetos de emissão de papel-moeda e os planos de criação de caixas de crédito para o fomento da economia colonial.

\section{Palavras-chave}

Rodrigo de Souza Coutinho; moeda; crédito; império português.

Códigos JEL B12. B31. N16. 


\section{Introdução}

Em Portugal, o século XVIII caracteriza-se pela construção de um sistema monetário relativamente estável apoiado no bimetalismo, com o abandono das desvalorizações da moeda que haviam caracterizado o período posterior à Restauração. O notável crescimento da oferta monetária com o afluxo do ouro brasileiro, por um lado, e uma atuação prudente do Estado no tocante às políticas monetárias desde 1688 , especialmente sem recorrer às desvalorizações em momentos fiscais críticos, por outro, seriam os pilares fundamentais dessa estabilidade (Sousa, 2006, p. 77-94). ${ }^{1}$

No entanto, os desequilíbrios fiscais e monetários da década de 1790 causados pelas guerras e revoluções do final da centúria alterariam o quadro vigente de aparente estabilidade do restante do século XVIII, tornando-se tema crucial dos escritos do reformismo ilustrado luso-brasileiro. Os homens de governo daquela época foram obrigados a pensar possíveis soluções para um império e uma monarquia que não dispunha mais da abundância do ouro brasileiro. Assunto crucial para a história do pensamento econômico, refletir sobre a moeda e o crédito era naquele momento definir o destino e a sobrevivência política e econômica da monarquia lusitana do Antigo Regime em meio às convulsões que atravessavam os dois lados do Atlântico. Essa redefinição de vínculos atingia tanto as relações exteriores dos Estados envolvidos como a própria dinâmica entre a Coroa e seus vassalos no reino e nos domínios ultramarinos.

O objetivo do presente texto é analisar as ideias sobre a moeda e crédito nos escritos do estadista português D. Rodrigo de Souza Coutinho do final do século XVIII, destacando, em particular, a dimensão do Brasil nessa análise. Ademais, busca-se enfatizar a importância das leituras smithianas do estadista no qual se houve mimetismo, também ocorreram transformações dessas influências ao aplicá-las aos projetos destinados à América portuguesa. Ambos aspectos procuram complementar as interpretações

1 É verdade também que ainda persistiam sérios problemas quanto à escassez de moeda metálica para as pequenas transações, sobretudo moedas de prata e de cobre. Ademais, a ausência de uma fonte interna de prata tornava Portugal e os domínios dependentes do suprimento espanhol. Da perspectiva das finanças do Estado português, passado o período mais opulento, o ouro brasileiro não correspondia diretamente a um montante elevado, alcançando entre 5 a 12\% das receitas totais entre 1762 e 1776 (Magalhães, 2011, p. 188-189). Contudo, nesse cálculo seria necessário considerar os efeitos indiretos da riqueza aurífera sobre a elevação geral dos contratos de impostos e o crescimento dos ganhos alfandegários do reino e dos domínios. 
existentes (Cardoso, 1988, 1989, 2001), bem outro estudo realizado sobre a questão da tributação em Souza Coutinho (Aidar, 2011). O artigo restringe-se ao período de atuação de $\mathrm{D}$. Rodrigo como embaixador em Turim e posteriormente secretário da Marinha e Domínios Ultramarinos, deixando-se para um momento ulterior a análise do período a partir de 1801, marcado pela presidência de Souza Coutinho no Erário Régio e pela transferência da Corte portuguesa para o Brasil.

A primeira seção apresenta as reflexões iniciais sobre a moeda e o ouro brasileiro realizadas por Souza Coutinho como embaixador em Turim, após indicar em traços gerais a abordagem da moeda no pensamento econômico português desde o final do século XVII. A segunda seção apresenta os projetos de emissão de papel-moeda na colônia surgidos durante a atuação de D. Rodrigo como Secretário de Estado dos Negócios da Marinha e Domínios Ultramarinos. Por fim, a terceira seção aborda os planos de criação de caixas de crédito para o fomento da economia colonial, particularmente das capitanias da Bahia e de Pernambuco.

\section{Leitor de Smith, observador da Itália}

Antes do final do século XVIII, notam-se algumas reflexões, ainda que intermitentes, sobre a moeda e o crédito no pensamento econômico português. Sob influência do pensamento escolástico e mercantilista, sobretudo espanhol, o século XVII marcaria o início das reflexões mais teóricas sobre a moeda em Portugal, especialmente nas obras de Fernão Rebelo (Tratado dos Câmbios, 1608) e de Duarte Gomes Solis (Discursos sobre los comercios de las Indias, 1622) (Almodovar e Cardoso, 1998, p. 19-22).

Se é possível conceber alguma perspectiva mercantilista sobre a moeda em Portugal desde o final do século XVII até meados do século XVIII ela está marcada por duas características principais: concepção circulacionista e fomento à produção nacional, sendo, portanto, uma visão mais elaborada do que o metalismo. ${ }^{2}$ A primeira ideia refere-se ao ideário do dinheiro como sangue do corpo político do reino (Caminha, 1817 [1675]; Gusmão, 1844 [1748]). Tal associação parece ter sido uma constante no pensamento econômico italiano (Davanzati), francês (Poulain, Montchrétien, Vauban e

2 Para uma visão geral do pensamento monetário em Portugal entre os séculos XVI e meados do século XVIII ver Cardoso (2014). 
Quesnay) e inglês (Hobbes e Petty) desde o final do século XVI até meados do século XVIII (Magalhães, 1967, p. 70-72).

A segunda característica marcante das ideias monetárias lusitanas no final dos Seiscentos até meados dos Setecentos pode ser indicada no fomento da política manufatureira como solução para uma saída estrutural de moeda do reino, fruto de condições comerciais desfavoráveis a Portugal antes e depois do Tratado de Methuen. Assim, é importante destacar a aproximação das diferentes políticas mercantilistas existentes desde o $3^{\circ}$ Conde de Ericeira até Pombal da corrente do mercantilismo "industrial" ou do colbertismo, como indica Calvet de Magalhães. Para essa vertente a obtenção de riqueza monetária pelo Estado ocorreria pelo aumento da produção industrial do país e não pelo controle direto do movimento monetário, distanciando-se portanto das correntes iniciais do metalismo (Magalhães, 1965-1966, p. 67-68).

A alegada identificação mercantilista entre moeda e riqueza deve ser vista com cautela nos escritores portugueses do final do século XVII. Na obra de Ribeiro de Macedo, por exemplo, ao condenar o entesouramento do dinheiro por meio da tributação nas mãos do Príncipe e ao enfatizar a circulação de moeda (Magalhães, 1967, p. 93, 103), a perspectiva do autor tende mais a associar moeda ao capital circulante, em termos modernos, do que ao estoque de riqueza. Se a moeda é enfatizada nesses escritos, as soluções tendem a olhar amiúde para questões muito vinculadas a desequilíbrios na produção, aspecto também ressaltado em outras análises (Cardoso, 2014, p. 798). Para Duarte Ribeiro de Macedo, a exportação de numerário era um mal decorrente de países com uma balança comercial desfavorável, tornando inúteis as leis que proibiam a exportação de numerário, as práticas de desvalorização monetária e as pragmáticas que coibiam o consumo (Magalhães, 1967, p. 73-80).

Ao colocar o desequilíbrio da balança comercial como causa essencial da saída de moeda em Portugal, Ribeiro de Macedo deslocava o centro da análise da política econômica para questões produtivas. Assim, a escassez monetária seria o resultado final de uma condição existente na esfera da produção. Sem o recurso ao império do Oriente, a solução apresentada por Duarte Ribeiro baseava-se no fomento das manufaturas no reino, que se efetivariam nas políticas manufatureiras empreendidas pelo $3^{\circ}$ Conde de Ericeira, D. Luís de Meneses (1632-1690): 
"(...) o único meio que há para evitar este dano, e impedir que o dinheiro não saia do reino, é introduzir nele artes (...) pela introdução das artes, se evita a introdução das fazendas, que os estrangeiros metem no reino, e teremos com que pagar as fazendas, e drogas que entrarem, sem que seja necessário pagá-las" (Caminha, 1817 [1675], p. 4).

Ao início do século XVIII, os afluxos do ouro brasileiro e a realização do Tratado de Methuen alterariam completamente o quadro monetário da economia portuguesa e seu império. Sem a modificação do quadro internacional, a única solução possível para saldar os déficits do comércio exterior português e, consequentemente, a saída permanente de metal do reino era aumentar as entradas dos recursos auríferos, seja por meio da redução do contrabando, seja pela introdução de novas formas de tributação, como proporia Alexandre de Gusmão. Na mesma linha de Ribeiro de Macedo, Gusmão seria favorável às restrições de importação dos produtos de luxo e à criação de manufaturas como paliativos à perda de metais preciosos (Cardoso, 2014, p. 803-804).

Um século depois de Ribeiro de Macedo e no contexto de grande declínio da produção aurífera brasileira, a moeda seria colocada novamente na análise central dos problemas da economia portuguesa como se observa dos escritos de D. Rodrigo de Souza Coutinho, mas o encaminhamento seria completamente diferente, absorvendo o afluxo de ideias do nascente liberalismo smithiano.

Tendo como padrinho de batismo o marquês de Pombal, D. Rodrigo de Souza Coutinho (1755-1812) seria educado no Colégio Real dos Nobres e na Universidade de Coimbra, onde realizaria estudos jurídicos. ${ }^{3}$ Assim como seu pai, Souza Coutinho seguiria a carreira diplomática, sendo nomeado Enviado extraordinário e ministro plenipotenciário na Sardenha em 1778. Antes de partir para a Itália, D. Rodrigo realizaria viagens por Madrid e Paris, conhecendo alguns ilustrados franceses, como D'Alembert e o Abade Raynal, e portugueses, como o médico Ribeiro Sanches e o duque de Lafões, que fundaria a Academia Real de Ciências de Lisboa. Em seu cargo diplomático, Souza Coutinho viveria um longo período em Turim, entre 1779 e 1796, onde acompanharia as diversas reformas ilustradas empreendidas pelo rei Vítor Amadeu III no Piemonte e por José II na Lombardia austríaca, sem deixar de atentar para as profundas mudanças que ocorriam em Portugal, Inglaterra e França.

3 Sobre a trajetória do ministro português consultar a excelente obra de Andrée Mansuy-Diniz Silva (Silva, 2002-2006), assim como Silva (2006) e, mais recentemente, Santos (2013). 
Em 1783, entre os ofícios expedidos por Souza Coutinho como embaixador em Turim delineiam-se as primeiras ideias do ilustrado sobre o funcionamento do papel-moeda. ${ }^{4}$ As observações de Souza Coutinho baseavam parte na experiência prática do reino piemontês e parte nas leituras realizadas de A Riqueza das Nações, apenas poucos anos após sua publicação.

Emitidos em 1745 e 1746 no reino do Piemonte e Sardenha durante a guerra da Sucessão Austríaca, a novidade desses bilhetes era sua garantia e sanção pelo poder do Estado em vez de ser decorrentes da expansão de crédito por agentes privados. A confiança estava alicerçada nas receitas do governo e inicialmente no pagamento de um prêmio anual de $4 \%$, aspecto depois suprimido conforme a circulação ganhava crédito. A despeito do entusiasmo de Souza Coutinho, a nova forma de crédito teve pouco impacto no financiamento das dívidas do Estado saboiardo (Storrs, 2013, p. 230).

O papel-moeda era apontado por Souza Coutinho como um substituto aos metais preciosos, que deveriam ser poupados para o emprego no comércio internacional, reservando o papel-moeda às trocas internas. Ao realizar essa economia do meio circulante mais valorizado, o papel-moeda justificava-se principalmente pelo "aumento de capitais que a nação emprega no seu comércio exterior" (Silva, 1993, v. 1, p. 33). A intepretação de Souza Coutinho está nitidamente calcada nas ideias de Smith sobre a circulação monetária. ${ }^{5}$ Para Smith, a substituição das moedas metálicas por papel-moeda serviria como um instrumento menos dispendioso de comércio. O papel-moeda seria utilizado no comércio interno e os metais preciosos no comércio externo, gerando lucro e aumento da renda líquida do país (Smith, 1996, v. 1, p. 301, 303).

A ideia essencial para o embaixador português era a perspectiva, adquirida pela leitura de Smith, de que a moeda metálica e o papel-moeda circulantes deveriam ser proporcionais e representativos do produto geral e da renda total da nação. Dessa forma, a circulação monetária estava intimamente vinculada à ideia de representação de uma riqueza real. Segundo Smith, o ouro e a prata representavam o preço de todas as outras mercadorias. A quantidade de metais preciosos existente em um país dependeria da demanda efetiva, ou seja, da demanda necessária para o pagamento dos

4 Extrato do ofício n. 40, 28 de maio de 1783 (Silva, 1993, v. 1, p. 31-34).

5 Sobre a teoria monetária e financeira de Adam Smith consultar, entre outros, as obras de Rist (1966), Boyer (1987), Duboeuf (1994) e Guerity (1994). 
rendimentos (renda da terra, salários e lucros) empregados na produção. Ao exceder essa demanda, os metais preciosos seriam exportados para outros países (Smith, v. 1, p. 420).

Para Souza Coutinho, emitir papel-moeda além do produto geral apenas geraria descrédito e desvalorização dos bilhetes, bem como o desaparecimento dos metais preciosos de circulação (Silva, 1993, v. 1, p. 31). O controle dessa emissão deveria ser, portanto, realizado de forma prudente por ministros hábeis e ilustrados. Ademais, ressaltava que estes deveriam ser motivados pelo interesse genuíno na economia pública, não a tratando como uma extensão da economia privada. $\bigcirc$ limite de emissão de papel-moeda indicado por Souza Coutinho e considerado "prudente" era correspondente a um quinto do metal circulante, uma observação claramente retirada da leitura de Adam Smith (Smith, v. 1, p. 302).

Em 1784, no seu "Discurso sobre o comércio de Itália relativamente ao de Portugal", os metais preciosos eram indicados por Souza Coutinho como um sinal representativo da riqueza, deslocando-se de acordo com a necessidade dessa representação: “(...) sendo certo que este sinal representativo das riquezas corre sempre para aqueles lugares onde há riquezas que representar" (Silva, 1993, v. 1, p. 99). Nessa análise, as transferências metálicas seriam decorrentes dos movimentos da balança comercial, sendo estes resultantes da prosperidade ou decadência dos países. Aponta, por exemplo, o caso das "nações que pela sua indústria acumularam os sinais representativos da riqueza" (Silva, 1993, v. 1, p. 100).

Para Souza Coutinho, se não havia tanta riqueza no país, haveria a necessidade de reduzir a quantidade de moeda que representa essa riqueza, sendo a saída de metais preciosos vista como um indício seguro de sua decadência. Ademais, na interpretação do embaixador português a abundância ou escassez de metais preciosos dependia da prosperidade nacional. ${ }^{6}$ Portanto, pode-se dizer que para o autor a quantidade de metais preciosos em circulação era o resultado da riqueza da nação, não a sua causa, em nítido contraste com o pensamento mercantilista de cariz metalista.

No entanto, a interpretação de Souza Coutinho não esteve isenta de ambiguidades. Em um mesmo parágrafo, indica como os metais preciosos eram representativos das riquezas e também uma "espécie de riqueza", que teria originado o comércio de câmbio e os bancos:

6 Discurso sobre o comércio de Itália relativamente ao de Portugal, 20 de outubro de 1784 (Silva, 1993, v. 1, p. 95-112, ver p. 99-100). 
"Deste modo no comércio geral das nações os metais preciosos, sendo representativos das riquezas puderam aumentar a circulação e vieram a ter um valor relativo às circunstâncias das nações, e de algum modo diferente do primeiro fim para que foram instituídos, vindo a ser também uma espécie de riqueza" (Silva, 1993, v. 1, p. 100).

Ainda residindo em Turim, D. Rodrigo não deixaria de intervir na política e na cultura portuguesa de sua época. Na sua famosa memória publicada pela Academia de Ciências de Lisboa, "Discurso sobre a verdadeira influência das minas dos metais preciosos na indústria das nações que as possuem, e especialmente a portuguesa" (1789), as indicações de Souza Coutinho acerca da relação entre metais preciosos e prosperidade nacional levar-no-iam a reconsiderar a importância das descobertas das minas para o desenvolvimento da "indústria" nas monarquias ibéricas. ${ }^{7}$

O embaixador procura refutar a ideia de que a descoberta das minas apenas geraria despovoamento e inflação, causando danos à indústria do país. Segundo Souza Coutinho, os descobridores das reservas de metais preciosos, agentes colonizadores, serviriam também como fonte de demanda para a agricultura e as manufaturas, compensando as perdas com o despovoamento do reino. Em um segundo momento, a demanda das regiões mineradoras teria o mesmo efeito que a uma balança comercial favorável, permitindo o crescimento do comércio e da indústria da metrópole. Para o embaixador, o aumento na quantidade de metais preciosos nas Américas resultaria na redução dos juros do dinheiro, aspecto já ressaltado por Locke, Law, Montesquieu, Turgot e Smith (Smith, 1996, v. 1, p. 352; Rist, 1966, p. 124).

A análise de Souza Coutinho pressupõe que a demanda das minas seria empregada dentro do comércio colonial, a riqueza acumulada serviria a propósitos produtivos e o aumento dos metais preciosos teria um efeito real pela expansão do crédito pela redução dos juros. Dessa forma, justifica-se a política mercantilista para o enriquecimento das nações, mas

7 Discurso sobre a verdadeira influência das minas dos metais preciosos na indústria das nações que as possuem, e especialmente a portuguesa, 1789 (Silva, 1993, v. 1, p. 169-173). Certamente a perspectiva de $\mathrm{D}$. Rodrigo é parte de um quadro mais amplo das explicações sobre a decadência do ouro em Minas Gerais. Segundo Laura de Mello e Souza teriam surgido três visões sucessivas. A primeira relacionava a pobreza ao extravio e ao contrabando, exemplo máximo dado pelas ideias de Martinho de Melo e Castro ao longo da década de 1780. A segunda explicação inicia-se com os memorialistas da Academia de Ciências de Lisboa, e também abarca D. Rodrigo de Souza Coutinho (na interpretação da autora), os quais argumentam que a redução aurífera seria causada pelas dificuldades extrativas e pela falta de tecnologia para ir além do ouro de aluvião. Ainda entre os memorialistas, surgiria uma terceira análise que associava o ouro com uma riqueza aparente e inconstante, questão a ser solucionada com a defesa do agrarismo (Souza, 2004, p. 58-65). 
dentro de um novo arcabouço teórico que colocava a expansão produtiva em primeiro plano.

Em um aspecto muito específico, a interpretação aqui exposta difere da análise clássica efetuada por Fernando Novais sobre a memória de Souza Coutinho ao considerar o papel da demanda das regiões mineradores e o aumento da oferta de crédito. Entende-se que a visão de Souza Coutinho vincula de forma complementar a oferta das manufaturas do reino à demanda colonial das áreas mineradoras, argumento que parece um tanto distante da defesa da indústria como condição necessária ao êxito da mineração, como apontado por Novais. ${ }^{8}$

Observa-se ademais, semelhanças entre a análise de Souza Coutinho e a de Adam Smith, para o qual a descoberta da América havia enriquecido a Europa, mas não por conta dos afluxos de metais preciosos, que apenas haviam reduzido de preço. Para Smith, as colônias representaram a abertura de novos mercados, o aumento da divisão do trabalho e melhoramento das forças produtivas. Tais conquistas seriam impossíveis nos antigos circuitos comerciais e resultaram no aumento da renda e das riquezas reais dos europeus (Smith, 1996, v. 1, p. 430-431).

No entanto, contrariamente à análise smithiana, Souza Coutinho refuta a interpretação inflacionária do aumento da oferta de metais preciosos ao indicar a economia das regiões mineradoras como regiões produtivas, suscetíveis portanto da produção de rendimentos que seriam empregados na compra dos produtos metropolitanos. Dessa forma, Souza Coutinho parece ter ampliado a análise smithiana ao considerar as colônias como espaços produtivos, onde seria possível aumentar a divisão do trabalho e alcançar benefícios mútuos por meio das trocas comerciais, como seria ressaltado e melhor desenvolvido posteriormente na famosa memória de D. Rodrigo, "Memória sobre o melhoramento dos domínios de Sua Majestade na América" (1797 ou 1798) (Silva, 1993, v. 2, p. 47-67). É verdade

8 Segundo Novais, a memória de Souza Coutinho indicava "depender a utilidade da lavra de minas do grau de desenvolvimento da metrópole e sobretudo da sua produção manufatureira; a ausência das manufaturas é que tornara perniciosas as minas, incidindo sobre uma economia mais adiantada elas seriam altamente benéficas. Assim, o desenvolvimento da metrópole passava a ser visto como condição para a assimilação das vantagens da exploração colonial, ao mesmo tempo que a pressupunha" (Novais, 1989, p. 236, grifos originais). E mais adiante: "a ideia principal [de Souza Coutinho] era a de que para poder aproveitar os efeitos positivos da mineração necessitava o país de industrializar-se. Ou noutros termos, os efeitos da exploração mineira eram danosos quando incidiam em país desprovido de manufaturas" (Novais, 1989, p. 282). 
que essa interpretação possui limites, uma vez que os espaços produtivos reconhecidos na colônia são eminentemente agrícolas, mantendo-se as manufaturas no reino.

$\mathrm{Na}$ análise de Souza Coutinho, a decadência econômica de Portugal teria se iniciado nos últimos anos do reinado de Dom João III (1521-1557), sendo agravada com a União Ibérica. As oportunidades de crescimento representadas pelas minas de ouro do Brasil ao início do século XVIII não seriam aproveitadas devido ao estabelecimento do Tratado de Methuen. Os déficits na balança comercial sorveriam todo o ouro brasileiro e destruiriam a possibilidade de desenvolvimento manufatureiro português. Os ganhos auríferos seriam vistos como apenas um atenuante para a situação de declínio, criando uma "riqueza aparente", posto que não estivesse fundamentada sobre a indústria. Embora não cite explicitamente Pombal, as medidas tomadas durante o reinado de Dom José I (1750-1777) tentariam evitar os danos do tratado com a Inglaterra (Silva, 1993, v. 1, p. 172-173).

Ainda no "Discurso..." sobre as minas de metais preciosos, a interpretação de Souza Coutinho aponta motivos reais para a decadência econômica portuguesa no século XVIII vinculados ao tratado, que "tinha quase reduzido [os portugueses] a ser colonos duma estranha metrópole [a Inglaterra]" (Silva, 1993, v. 1, p. 173). Assim, pode-se observar que o problema central não estava no acúmulo de metais preciosos, mas na perda da capacidade de reter esses montantes, devido ao déficit estrutural da balança comercial, o que impedia de empregá-los de forma produtiva para o fomento da indústria portuguesa.

As observações de Souza Coutinho mostram-se bastante distintas às considerações de Adam Smith sobre a relação entre o tratado de Methuen e a entrada de ouro brasileiro na Inglaterra. Para Smith, as transferências auríferas de Portugal para as ilhas britânicas eram decorrentes da falta de demanda por circulação monetária no comércio interno. Segundo Smith, era mais vantajoso colocar o ouro em circulação, enviando-o ao exterior onde seria possível adquirir mercadorias estrangeiras, do que mantê-lo entesourado e ocioso (Smith, 1996, v. 2, p. 49).

\section{Um império de papel-moeda}

A partir de setembro de 1796, D. Rodrigo seria nomeado para a Secretaria de Estado da Marinha e Domínios Ultramarinos, ocupando o lugar de Mar- 
tinho de Mello e Castro, permitindo-lhe empreender tentativas de implementação de suas ideias de reforma do reino e do império, que possuíam origens na missão em Turim, mas seriam modeladas pelas novas circunstâncias do expansionismo napoleônico. Muitos projetos intentados só teriam algum êxito em realidade a partir de 1801, quando ocuparia o cargo de Presidente do Real Erário e Ministro e Secretário de Estado da Fazenda. Como presidente do Erário Régio, D. Rodrigo conseguiria realizar alguns dos projetos aos quais almejava no cargo anterior quanto à extinção dos contratos do sal e da pesca das baleias, além das reformas da administração das minas de ouro e diamantes. Em 1803, após uma série de resistências internas e hostilidades francesas, D. Rodrigo pediria demissão do seu cargo.

$\mathrm{Na}$ sua famosa "Memória sobre os melhoramentos dos domínios de Sua Majestade na América" (1797 ou 1798), Souza Coutinho empregaria seus conhecimentos obtidos pela leitura de obras teóricas de economia e pela observação das reformas realizadas no reino do Piemonte e Sardenha durante sua atuação como embaixador em Turim. ${ }^{9}$ Ao lado das melhorias e alterações na tributação, administração fiscal e escrituração das contas fiscais, a reforma monetária e financeira era considerada como um dos pilares essenciais da recuperação fazendária do Estado imperial português. A Fazenda é compreendida como o principal eixo a sustentar os vínculos entre o centro e as partes da monarquia portuguesa, do qual dependiam todos os demais, e que "em última análise decid[ia] da grandeza do soberano e da felicidade dos povos". No que respeitava à moeda e ao crédito, o financiamento do Estado vinha em primeiro lugar, seguido do fomento econômico da agricultura, indústria e comércio (Silva, 1993, v. 2, p. 54-55). O vínculo entre emissão monetária e fomento ao crédito é vista de forma muito geral, indicando que, nas colônias, o papel-moeda seria útil "para aumentar e animar os ramos [novos e pré-existentes] de cultura" (Silva, 1993, v. 2, p. 62).

Na memória, Souza Coutinho reitera a visão expressa nos escritos de 1783 e no discurso sobre o comércio luso-italiano em 1784. A moeda é considerada pelo ministro como "o sinal representativo das riquezas de cada país, e serve de unidade para as trocas dos efeitos que diariamente se fazem" (Silva, 1993, v. 2, p. 60). A moeda metálica é um "sinal representativo universal", da qual o papel-moeda seria uma representação derivada. va, 1993, v. 2, p. 47-75). 
Para Souza Coutinho, a circulação de moeda metálica e de papel-moeda dependia das transações realizadas entre as nações e dentro dos países. Mais uma vez tais trocas externas e internas estipulam o limite máximo de circulação do papel-moeda, fronteira que os soberanos deveriam respeitar estritamente.

Subjacente a essa ideia, estava a crença de que os governos agora devem respeitar as leis naturais da economia, não podendo submeter o valor da moeda ao "arbítrio e vontade de cada país", recomendação que certamente condenava as alterações monetárias realizadas em Portugal no século XVII. O valor da moeda estabelecido pelo universo econômico não é tratado somente como uma lei natural, mas também como um atributo racional e evidente. É percebido como uma "verdade geométrica" e uma "certeza irrefragável", sobre as quais governo ilustrado da economia deve ajuizadamente ponderar (Silva, 1993, v. 2, p. 61). Esse aspecto é particularmente interessante, pois mostra um nítido contraste com as políticas monetárias mercantilistas mais antigas. Se em Duarte Ribeiro de Macedo no último quartel do século XVII já existe a crítica às desvalorizações monetárias, em Souza Coutinho a precaução torna-se proibição e interdição, reverberando o credo fisiocrata e liberal acerca da constituição de uma esfera autônoma da economia que os soberanos devem respeitar a todo custo.

O encaminhamento da reforma monetária nos domínios ultramarinos possuía na substituição parcial da moeda provincial por papel-moeda um eixo central. ${ }^{10}$ De início, Souza Coutinho trata as moedas provinciais como meios de pagamento similares ao papel-moeda. Assim como as últimas, as primeiras não devem exceder o seu limite de circulação proporcional às transações efetuadas na economia. Contudo, há pequenas diferenças. Da mesma maneira como as moedas metálicas comuns, as moedas provinciais possuíam valor intrínseco. Daí decorria uma regra curiosa observada pelo ministro. Uma vez que as moedas provinciais circulassem fora do

10 Sobre as origens da criação da moeda provincial ver Lima (2005) e Puntoni (2012). Deve-se notar que se antes do final do século XVIII ainda não havia a introdução de papel-moeda na colônia, o contato com outros instrumentos de pagamento, além das moedas metálicas, não era completamente desconhecido dos habitantes da América portuguesa. Circulavam como meios de pagamento, com atributos de quase-moeda, escritos da Alfândega, bilhetes dos Armazéns de Guiné e Índia, apólices das companhias mercantis do Grão-Pará e Maranhão e de Pernambuco e Paraíba após 1766 e finalmente, desde 1772, os bilhetes da Real Extração dos Diamantes do Tejuco (Sombra, 1938, p. 225-232). Para Fortunée Levy, os bilhetes da extração representam o primeiro papel-moeda colonial, sendo até mesmo recebidos no pagamento dos tributos e circulando fora do Distrito Diamantino, alcançando áreas para além da capitania de Minas Gerais (Levy, 1941, p. 274). 
seu escopo original, ou seja, da região para a qual foram cunhadas, essas moedas perderiam seu valor extrínseco e seriam trocadas somente pelo seu conteúdo metálico (Silva, 1993, v. 2, p. 61).

No raciocínio de Souza Coutinho havia, portanto, espaços monetários muito bem delimitados a hierarquizar a circulação dos meios circulantes: moeda de ouro e metais preciosos para o comércio internacional, papel-moeda e moedas provinciais para o comércio interno ao império português. Dessa forma, compreende-se perfeitamente a proposta de Souza Coutinho em substituir a moeda provincial por papel-moeda, inserindo a circulação fiduciária no regime colonial e prolongando suas primeiras reflexões sobre o tema realizadas em Turim e apoiadas em Smith.

Mais uma vez observa-se a leitura atenta da obra de Smith por D. Rodrigo. Discutindo a situação das colônias inglesas na América do Norte, notava Smith como a utilização do papel-moeda poderia suprir a escassez de moeda metálicas de ouro e prata em circulação. Smith indica que o ouro e prata deveriam ser poupados e utilizados na ampliação do capital empregado na expansão da capacidade produtiva, sobretudo agrícola (Smith, 1996, v. 2, p. 386-387).

Souza Coutinho informa claramente em sua "Memória..." que cada capitania teria um papel-moeda específico (Silva, 1993, v. 2, p. 61), justificando a medida com o objetivo de evitar fraudes e falsificações. Quando comparada à antiga circulação das moedas provinciais e em nítido contraste à prática monetária de sua época, ${ }^{11}$ a proposta do ministro indicava uma fragmentação maior dos circuitos monetários da colônia, aprofundando a regionalização, uma vez que as moedas provinciais podiam circular por zonas mais amplas, entre as capitanias, enquanto que o papel-moeda estava circunscrito a espaços menores. De forma quase física, os limites à circulação seriam delimitados pela criação das casas de troco.

Esse último aspecto parecia replicar uma situação existente nas regiões mineradoras. As fronteiras monetárias lícitas das minas eram controladas pelos registros, que juntamente, com as Casas de Moeda e as Casas de Fundição, constituíam as instituições principais da vida monetária colonial (Sombra, 1938, p. 190). Nos registros, o ouro era tributado e trocado 11 Em 1789, por exemplo, segundo os comerciantes da praça de Salvador, havia o "extravio que dela [moeda provincial] se tem feito para as capitanias do Rio de Janeiro e Pernambuco e porque todo o ouro que vem de Minas e da Costa da Mina é reduzido na Casa da Moeda a peças de $6 \$ 400$, que imediatamente são transportadas para Portugal e para a Ásia" (Sombra, 1938, p. 251). 
por moedas que podiam circular fora da região mineradora. Dessa forma, os registros buscavam delimitar uma fronteira ao mesmo tempo fiscal e monetária.

Segundo o ministro, a emissão de papel-moeda nas capitanias deveria respeitar a proporção de $66,7 \%(2 / 3)$ dos rendimentos fiscais respectivos, valor um pouco inferior à "regra geral" estipulada que era $75 \%$ das receitas tributárias (Silva, 1993, v. 2, p. 61). Tomando-se os dados fiscais das capitanias para o ano de 1797, a data mais provável em que a memória de Souza Coutinho foi apresentada (Silva, 1993, v. 2, p. 47, nota 1), observa-se que a emissão proposta pelo ministro estava bem abaixo do idealizado (Tabelas 1 e 2). A diferença entre a emissão projetada e a emissão ideal baseada na proporção dos rendimentos fiscais totais das capitanias era em média de cerca de $40 \%$, sendo que a capital do vice-reino era o caso mais gritante onde a emissão projetada de papel-moeda teria que ser $60 \%$ mais elevada para se equiparar à emissão idealizada (Tabela 2, coluna I). Souza Coutinho não indica exatamente quais devem ser a receitas fiscais a serem observadas, se incluem ou não os empréstimos e outras entradas, aspecto que evidentemente conduz a outras proporções nos montantes a serem emitidos.

No entanto, pode ser observada uma equivalência entre a emissão projetada e as receitas provenientes de empréstimos (Tabela 2, coluna IV). Sabe-se que tais recursos eram amiúde constituídos por dívidas de curto prazo, letras passadas pela Real Fazenda, que acabavam adquirindo propriedades de quase-moeda pela sua circulação entre os agentes econômicos. D. Rodrigo sugere esse vínculo entre a dívida flutuante e os projetos de emissão ao indicar que o papel-moeda serviria "para extinguir as dívidas não fundadas das capitanias". A ideia do ministro era realizar a consolidação dessa dívida flutuante por meio de rendas vitalícias ou permanentes, ou mesmo recorrendo ao sistema de loterias, que permitisse criar um sistema de amortização das dívidas (Silva, 1993, v. 2, p. 62). Informações posteriores tendem a indicar o processo teve algum sucesso no caso de empréstimos realizados no Rio de Janeiro, Bahia e Pernambuco em $1796 .{ }^{12}$

12 O relatório do Ministério da Fazenda apresenta, entre os dados da dívida interna fundada no "Quadro da dívida pública até 31 de dezembro de 1828", alguns empréstimos realizados para as capitanias do Rio de Janeiro, Bahia e Pernambuco em 1796 respectivamente nos valores de 352:554\$191, 217:753\$333 e 21:750\$000 réis. No entanto, é difícil verificar se existiriam outros empréstimos do final do século XVIII em meio da dívida pública interna flutuante das províncias na primeira década independente (Brasil, 1829, $2^{a}$ parte). 
Tabela 1 Proposta de emissão de papel-moeda e receitas fiscais para capitanias brasileiras (em réis, 1797)

\begin{tabular}{lrr|r|r|r|r}
\hline & $\begin{array}{r}\text { (A) } \\
\text { Emissão } \\
\text { proposta }\end{array}$ & Emissão ideal & $\begin{array}{r}\text { (B) } \\
\text { Receitas totais } \\
\mathbf{( 1 7 9 7 )}\end{array}$ & $\begin{array}{r}\text { Rendimentos } \\
\text { próprios } \\
\mathbf{( 1 7 9 7 )}\end{array}$ & $\begin{array}{r}\text { Empréstimos } \\
\text { outras entra- } \\
\text { das (1797) }\end{array}$ \\
\hline $\begin{array}{l}\text { Rio de Janeiro, Santa } \\
\text { Catarina e Rio Grande }\end{array}$ & $200: 000 \$ 000$ & $487: 682 \$ 707$ & $731: 524 \$ 060$ & $480: 862 \$ 404$ & $250: 661 \$ 656$ \\
\hline Bahia & $200: 000 \$ 000$ & $385: 014 \$ 295$ & $577: 521 \$ 443$ & $387: 763 \$ 790$ & $189: 757 \$ 653$ \\
\hline Minas Gerais & $150: 000 \$ 000$ & $234: 165 \$ 199$ & $351: 247 \$ 798$ & $299: 112 \$ 063$ & $52: 135 \$ 733$ \\
\hline Pernambuco & $150: 000 \$ 000$ & $190: 421 \$ 991$ & $285: 632 \$ 986$ & $261: 096 \$ 203$ & $24: 536 \$ 233$ \\
\hline Maranhão & $100: 000 \$ 000$ & s.d. & s.d. & s.d. & s.d. \\
\hline Goiás e Mato Grosso & $100: 000 \$ 000$ & s.d. & s.d. & s.d. & s.d. \\
\hline São Paulo & $50: 000 \$ 000$ & s.d. & s.d. & s.d. & s.d. \\
\hline Pará & $50: 000 \$ 000$ & s.d. & s.d. & s.d. & s.d. \\
\hline Total & 1.000 .000 .000 & & & & & \\
\hline
\end{tabular}

Fonte: Silva (1993, v. 2, p. 61) e Guimarães (2009, p. 126-129).

Tabela 2 Comparação de emissão de papel-moeda com os rendimentos das capitanias

\begin{tabular}{l|r|r|r|r}
\hline & $\begin{array}{r}\text { (I) } \\
\text { A/B }\end{array}$ & $\begin{array}{r}\text { (II) } \\
\text { A/C }\end{array}$ & $\begin{array}{r}\text { (III) } \\
\text { A/D }\end{array}$ & $\begin{array}{r}\text { (IV) } \\
\text { A/E }\end{array}$ \\
\hline $\begin{array}{l}\text { Rio de Janeiro, Santa } \\
\text { Catarina e Rio Grande }\end{array}$ & $41,0 \%$ & $27,3 \%$ & $41,6 \%$ & $79,8 \%$ \\
\hline Bahia & $51,9 \%$ & $34,6 \%$ & $51,6 \%$ & $105,4 \%$ \\
\hline Minas Gerais & $64,1 \%$ & $42,7 \%$ & $50,1 \%$ & $287,7 \%$ \\
\hline Pernambuco & $78,8 \%$ & $52,5 \%$ & $57,5 \%$ & $611,3 \%$ \\
\hline Média & $58,9 \%$ & $39,3 \%$ & $50,2 \%$ & $271,1 \%$ \\
\hline
\end{tabular}

Fonte: Tabela 1.

Com relação à região mineradora, a intenção de Souza Coutinho era abolir a circulação de ouro em pó e consequentemente as Casas de Fundição. Estas seriam substituídas por Casas de Permuta e Casas de Moeda. O projeto seguia a proposta representada em 1783, e renovada em 1791, pela Junta da Fazenda de Minas Gerais de extinguir a circulação em ouro em pó e introduzir a moeda provincial de ouro e prata na capitania (Sombra, 1938, p. 232; Cunha, 2012). No entanto, há algumas diferenças. Os projetos da junta tencionavam cunhar moeda metálica enquanto que o projeto de D. Rodrigo estava baseado na emissão de papel-moeda. 
Os montantes também eram distintos. A junta aconselhava a introdução de moeda na quantia de 100 contos de réis, em 1783, e posteriormente de 400 a 600 contos de réis, em 1791, contudo o ministro desejava a emissão de apenas 150 contos. A quantia pretendida pela junta em 1791 era superior às receitas totais da capitania (Cunha, 2012). De fato, excediam em muito à capacidade fiscal da região, mesmo que se considerasse o valor mínimo pretendido de 400 contos. Vale lembrar que em 1797, ano mais provável da memória de $\mathrm{D}$. Rodrigo, os rendimentos da capitania mineira totalizavam 285 contos de réis (Guimarães, 2006, p. 128).

Para realizar o plano da junta, o Estado português deveria transferir metais preciosos para a economia mineira, medida completamente impensável tanto no contexto específico da conjuntura bélica do final do século, a demandar recursos crescentes do Estado, quanto pela posição de Minas Gerais de fornecedora secular de recursos para a monarquia. Mesmo que fosse emitido apenas papel-moeda, como desejado por D. Rodrigo, o valor excederia à regra de ouro de $2 / 3$ idealizada pelo ministro, o que se pode conjecturar a partir das outras observações de Souza Coutinho em matéria monetária, causaria apenas desvalorização do meio de pagamento.

Com relação às Casas da Moeda, o projeto de D. Rodrigo era bastante curioso. Previa uma completa inversão da situação vigente, com a extinção das Casas da Moeda do Rio de Janeiro e da Bahia e a criação de uma Casa da Moeda em Minas Gerais e outra em Goiás. Aparentemente não apresentava nenhum argumento palpável para o término das instituições nas antigas capitanias, incluindo, de forma paradoxal, seu destemor diante da criação de Casas da Moeda falsas. Nesse ponto específico, Souza Coutinho é completamente absolutista: "logo que haja a menor suspeita, conservar as devassas abertas, visitar as correspondências, estabelecer penas prontas e muito rigorosas contra os que forem apreendidos em flagrante delito de tal natureza" (Silva, 1993, v. 2, p. 62).

Mesmo com a timidez do projeto de emissão de Souza Coutinho, o ministro procurava fomentar a confiança e a legitimidade da nova moeda a ser posta em circulação tanto pela inclusão de um circuito fiscal-monetário, via recebimento de tributos em papel-moeda, quanto pela criação de novas instituições regulatórias por meio das Casas de Troco.

Cabe notar que a produção de Souza Coutinho praticamente não considera a produção memorialista da época. No reino, Tomás Antônio de Vila- 
nova Portugal e Domingos Vandelli e produziram escritos sobre temas monetários e financeiros na década de 1790 (Cardoso, 1991, v. 3, p. 167-173; Serrão, 1994), mas não são citados por Souza Coutinho nos escritos coligidos por Andrée Mansuy-Diniz Silva (Silva, 1993). Quanto ao ilustrados luso-brasileiros, aparentemente os temas monetários e financeiros ocupam espaço marginal e igualmente não há indícios de trocas intelectuais com Souza Coutinho nesse campo específico. As breves considerações de José Joaquim de Azeredo Coutinho sobre a moeda como signo representativo sugerem influências ecléticas de Montesquieu, Forbonnais e Smith (Pedreira, 1992, p. XXVI-XXVII; p. 104-105, nota 156).

\section{As propostas das caixas de crédito}

A ideia da criação de instituições de crédito no fomento econômico não era matéria completamente desconhecida em Portugal antes do final do século XVIII. Em 1698, um desembargador do Paço, Diogo Marchaã Themudo, defendia a introdução dos montes de piedade, como ocorria na Espanha, que realizassem empréstimos aos lavradores (Dias, 1956, p. 139). No século XVIII, o médico Ribeiro Sanches em seus apontamentos sobre o comércio de Portugal, escritos em 1748, indicava a necessidade de um banco e de jurisdição própria para as letras de câmbio. Em suas Cartas para a educação da mocidade (1760), Ribeiro Sanches defenderia a expansão da monetização da economia, a utilização do crédito e a formação de bancos como medidas para o fomento da circulação de riqueza. Calvet de Magalhães aponta a influência do ensaio Of Money, escrito por David Hume em seus Political Discourses (1752), sobre as ideias monetárias do médico português (Magalhães, 1968, p. 13-23).

Uma das primeiras reflexões de Souza Coutinho sobre o papel do crédito no crescimento econômico pode ser observada em seus escritos sobre a agricultura no Piemonte ao final da década de $1780 .{ }^{13}$ Essas reflexões seriam abonadas e publicadas por Arthur Young, que elogiava o embaixador português, tendo-o conhecido em Turim. No texto, entre os fatores para o êxito da agricultura piemontesa, Souza Coutinho elencava o "baixo juros

13 Reflexóes políticas sobre os motivos da prosperidade da agricultura desde país [Piemonte], que servem a fazer ver praticamente as vantajosas consequências dos sábios princípios adoptados, 1789 (Silva, 1993, v. 1, p. 141-149). 
dos cabedais, e a facilidade que se lhes concede para se verterem e derramarem em benefício das campanhas" (Silva, 1993, v. 1, p. 142).

Citando e seguindo Smith, Souza Coutinho apontava que a prosperidade da agricultura era proporcional à quantidade de capital empregado, que, por sua vez, dependia da taxa de juros. Assim, quanto menor a taxa de juros, maior seria o desenvolvimento agrícola. No Piemonte, indicava o embaixador português, a restrição legal e estado próspero da sociedade haviam contribuído para uma taxa de juros de 3\% (Silva, 1993, v. 1, p. 144).

O estabelecimento de um banco público em Portugal seria claramente indicado nas notas de Souza Coutinho à memória "Reflexões sobre a fiscalidade e as finanças de Portugal" (1786). As notas a esse escrito seriam realizadas pouco depois da Revolução Francesa, podendo-se datá-las de 1791 visto que Souza Coutinho comenta o recente estabelecimento de um banco público nos Estados Unidos, que ocorreria naquele ano.

Segundo o embaixador português, um banco público seria útil para facilitar o comércio, reduzir os juros, financiar o Estado, realizar empréstimos para objetos de utilidade pública e servir de caixa de depósito aos comerciantes. Vê-se bem que a proposta desejada por Souza Coutinho buscava tanto servir ao financiamento do Estado quanto ao financiamento do comércio. Empréstimos a fábricas não são definidos pelo estadista.

Ainda nessas notas escritas em 1791, Souza Coutinho comentaria uma passagem do economista escocês James Steuart, onde esse afirmava, no seu An Inquiry into the Principles of Economy (1767), que o estabelecimento de bancos em países dependentes do produto de suas minas de metais preciosos para o pagamento da balança comercial apenas aceleraria a sua ruína. Steuart indica os casos de Portugal e Espanha, mas ressalta que esse aspecto pode ser generalizado para qualquer país nessa situação. A citação do parágrafo completo da obra de Steuart comentada por Souza Coutinho é a seguinte:

\footnotetext{
"But banks in prosperous trading nations sit down with casual and temporary inconveniences; and exchangers carry on a profitable trade, whether the nation be gaining or losing all the while. For such nations, and such only, are banks advantageous. Were banks established in Spain, Portugal, or any other country which pays a constant balance from the produce of their mines, they would only help on their ruin a little faster" (Steuart, 1767, v. 2, p. 175).
}

Souza Coutinho apontaria que a balança comercial desfavorável de Portugal poderia ser corrigida caso o reino "abrisse os olhos e (...) animasse 
a agricultura, artes e comércio". Ademais, também recordaria os escritos de Smith sobre papel-moeda, bancos públicos e os bancos escoceses. Souza Coutinho não negaria a possibilidade de falência desses últimos, mas afirma que "até quebrando, fizeram um bem real ao comércio e indústria do país que tinham feito reviver por meio de uma ativa circulação" (Silva, 1993 , v. 1, p. 239).

O retorno de Souza Coutinho a Portugal, por um lado, e as prementes necessidades financeiras do Estado português, por outro, tornariam o tema do crédito e da consolidação da dívida pública temas mais frequentes nos escritos do ministro, mesmo durante sua atuação na Secretaria de Estado da Marinha e dos Domínios Ultramarinos. Após 1790, os pagamentos atrasados e as despesas com as campanhas militares no Roussillon e na Catalunha, aliado à insuficiência na coleta da receita tributária, levariam o governo português a alterar o financiamento da dívida estatal até então baseado em tenças e padrões de juros reais. Conforme expressa Hespanha (1993), tem-se o ocaso do reequilíbrio do orçamento ordinário que predomina no longo período de 1700 a 1810 devido às agruras do Tesouro com as guerras contra a França revolucionária.

Além da reforma dos tributos e da administração fazendária no reino e nos domínios, as opções possíveis para o financiamento do Estado português ao final dos Setecentos eram o atraso no pagamento das despesas, compondo uma medida paliativa de curto prazo; o recurso aos de títulos públicos transferíveis por endosso e, por último, a emissão de papel-moeda (Madureira, 1994; Cardoso, 1989, p. 151-157). Objeto de preocupação para Souza Coutinho, é essa terceira opção que passa a predominar a partir do início de 1797, com duas ampliações do empréstimo do ano anterior e a emissão de apólices inferiores a 50\$000 réis, ocorreria a monetização da dívida pública portuguesa e o início da circulação de papel-moeda em Portugal. Assim como os assignats da França revolucionária, o papel-moeda português, de curso forçado, sofreria grande desvalorização no rebate por moeda metálica. Os valores emitidos eram cada vez menores $(50 \$ 000$ em 1797, $12 \$ 800$ e $6 \$ 400$ réis em 1799), indicando o agravamento da situação financeira da monarquia (Cardoso, 1989; Madureira, 1994).

Os escritos de Souza Coutinho entre 1796 e 1800 permitem acompanhar detalhadamente os debates travados sobre as relações entre papel-moeda, dívida pública e bancos públicos. De forma geral, a proposta do ministro era fundar e consolidar essa dívida flutuante de pequenas apóli- 
ces/papel-moeda por meio da criação de caixas de amortização e bancos públicos. Portanto, a discussão sobre as instituições financeiras planejadas por $\mathrm{D}$. Rodrigo movimenta-se entre a questão do fomento ao crescimento econômico, por um lado, e o problema da consolidação e resgate do papel-moeda utilizado para o financiamento do Estado, por outro.

Não obstante esses aspectos gerais, o debate da questão creditícia nos projetos imperiais do ministro pode ser parcialmente apartado das preocupações que se acumulavam na capital portuguesa, permitindo separar a análise entre os centros e as partes da monarquia. Conforme já apontado, a matéria financeira e monetária abordada na "Memória sobre os melhoramentos dos domínios de Sua Majestade na América" tratava apenas da questão do papel-moeda e continha breves notas sobre a problema da consolidação da dívida flutuante das capitanias.

É olhando para as indicações do ministro para o interior do reino e para as leituras de D. Rodrigo que encontraremos similaridades com as medidas destinadas aos domínios ultramarinos. De forma curiosa, pode-se dizer que há uma relação muito mais próxima entre o projeto do Banco Real Brigantino de 1797 e o Banco do Brasil criado em 1808 do que entre esse último e as caixas de crédito aconselhadas por Souza Coutinho aos governadores das capitanias em 1799 e 1800.

Em junho de 1798, o ministro português sugeria a criação de uma caixa de crédito ou banco particular para a província do Alentejo. ${ }^{14} \mathrm{D}$. Rodrigo concebe tal projeto entre os diversos meios para fomentar o crescimento econômico na região, mas especialmente o estímulo à agricultura, que seria o meio "mais fácil e natural de aumentar a povoação e riqueza do Alentejo". A instituição creditícia fornecia fundos aos proprietários, permitindo-os ter o capital necessário para o cultivo das terras e a produção de gado, bem como realizar melhorias nas propriedades agrícolas, erigir casas, oficinas, armazéns e até mesmo prados artificiais. $O$ propósito da medida era criar "uma classe de negociantes-agricultores", que tinha na Inglaterra seu exemplo mais destacado (Silva, 1993, v. 2, p. 162).

A inspiração para D. Rodrigo era o exemplo dos bancos escoceses e ingleses e das caixas de crédito da Silésia, região da Prússia. Mais uma vez Souza Coutinho aparece como um leitor aplicado d'A Riqueza das Nações. Nela, Smith destaca o papel dos bancos de emissão no crescimento ecode uma caixa de crédito ou banco particular, 13 de junho de 1798 (Silva, 1993, v. 2, p. 161-164). 
nômico da Escócia, que possuía apenas um quarto de meio circulante em moeda metálica (Smith, 1996, v. 1, p. 305-306). Segundo Smith, "os negócios do país [eram] quase inteiramente efetuados com notas de emissão dessas sociedades bancárias, notas essas com as quais se costuma[va] fazer compras e pagamentos de todos os tipos" (Smith, 1996, v. 1, p. 305).

As caixas de crédito da Silésia, por sua vez, haviam sido criadas durante o reinado de Frederico, o Grande, na Prússia. Tida como uma das inovações mais importantes do monarca, as Landschaften eram instituições de crédito rural destinadas exclusivamente à aristocracia fundiária para a melhoria de suas propriedades. A primeira Landschaft foi criada na Silésia em 1769, sendo depois fundadas mais instituições semelhantes em outras três regiões prussianas até a década de 1780. As notas das associações circulavam como notas bancárias, a exemplo do que ocorria com os bancos de emissão. Os proprietários, que podiam hipotecar até metade ou dois terços do valor de suas terras, tiveram acesso a um crédito relativamente barato em um contexto de crescimento dos preços dos grãos, aspecto que levou a um processo especulativo fundiário (Berdahl, 1988, p. 78-80).

Contrariamente às caixas de crédito da Silésia, o projeto para o Alentejo concederia empréstimos a todos os particulares com base em bens de raiz. A proposta de Souza Coutinho para o desenvolvimento do Alentejo era a criação de uma sociedade creditícia para empréstimos hipotecários com capital total de 120.000 .000 cruzados, divididas em 600 ações de 200.000 cruzados. D. Rodrigo não indica o limite máximo total de emissão de bilhetes de crédito, apenas aponta que estes deveriam ser emitidos com valor até 900.000 cruzados e emprestados aos agricultores com juros de $4 \%$ e no prazo de 13 anos. Os acionistas receberiam dividendos no valor de $6 \%$ ao ano. Assim como o Banco Brigantino, a sociedade teria o direito de cobrar os empréstimos com dívidas da Real Fazenda. Os tomadores de empréstimos deveriam assegurar a existência de renda da fazenda para o pagamento da hipoteca e quais seriam as benfeitorias a serem realizadas (Silva, 1993, v. 2, p. 162-163).

No ano seguinte, em 10 maio de 1799, D. Rodrigo apresentaria praticamente o mesmo plano de caixa de crédito ao governador da capitania da Bahia, D. Fernando José de Portugal (Silva, 1993, v. 2, p. 45-47). Em carta posterior, informava-se que os objetivos da caixa eram criar um meio de pagamento representativo da riqueza, sem o ônus de ser em metais preciosos (como já indicava Smith), conceder empréstimos a juros baixos 
para a agricultura e a exportação de gêneros da capitania e, por fim, permitir o pagamento regular das despesas do governo da capitania (Silva, 2006, p. 329-330). Segundo Andrée Mansuy-Diniz Silva, o plano "constitui a primeira tentativa, infelizmente gorada, de introdução no Brasil de um banco privado a benefício da agricultura" (Silva, 1993, v. 2, p. 38, nota 1). As únicas diferenças com relação à sociedade de crédito alentejana era a pequena diferença no prazo para o pagamento das hipotecas (de 13 a 14 anos) e a permissão para descontar letras de câmbio, endossadas por duas ou três firmas.

Ainda em maio de 1799, o tema das caixas de crédito aparece em uma carta régia para o governador interino, o bispo Azeredo Coutinho, e redigida por D. Rodrigo, mas assinada em nome da rainha D. Maria I pelo príncipe regente D. João (Silva, 2006, v. 2, p. 317). ${ }^{15}$ No ofício, a Coroa autoriza o governador interino a estabelecer "caixas de crédito, circulação e desconto a favor da agricultura e do comércio", que deveriam ser criadas ao lado de companhias de seguros.

Observa-se a ampliação do escopo da caixa de crédito proposta para Pernambuco em relação ao projeto para a Bahia dado que a primeira poderia conceder empréstimos hipotecários para comerciantes, tendo por garantia suas mercadorias ("efeitos"). Além de realizar empréstimos com garantias, tais caixas poderiam emitir bilhetes pagáveis à vista, como ocorria com as instituições propostas para o Alentejo e a Bahia.

No projeto para Pernambuco, nota-se que as disputas entre particulares, ou seja, a jurisdição contenciosa, estavam submetidas às Mesas de Inspeção, podendo-se apelar à Real Junta do Comércio em negócios superiores a $400 \$ 000$ réis. Tal ponto não havia sido tratado nos planos para as outras caixas.

Por motivos diferentes, tanto o projeto para Bahia quanto o enviado para Pernambuco não obtiveram êxito. Em maio de 1800, o governador D. Fernando José de Portugal informava ao ministro as dificuldades em colocar o plano em execução tanto pela falta de numerário em circulação quanto pela ausência de um bom número de negociantes e acionistas interessados na caixa. Com relação ao segundo aspecto, o comentário do governador revelava o caráter individualista, pessoal e molecular da concessão de crédito na capitania: "cada um dos comerciantes desta praça, em 15 Carta régia para o Bispo de Pernambuco e governadores interinos dessa capitania, 19 de maio de 1799 (Silva, 2006, p. 323-326). 
particular, é uma Caixa ou Fundo de cada um dos lavradores, por consistir o comércio da Bahia em suprir aos do tabaco e açúcar geralmente de todos os gêneros, dinheiros, fazendas e escravos, recebendo em seu pagamento as colheitas e trabalhos dos mesmos lavradores" (Apud Silva, 1993, v. 2, p. 47, nota 4). Pode-se entender a recusa do projeto como parte das resistências dos comerciantes em transferirem para uma instituição coletiva as relações de crédito que possuíam com os produtores agrícolas, bem como uma intervenção séria no tráfico de escravos realizado na capitania. Patrícia Valim aponta também o interesse do governador da Bahia em proteger a influência econômica e política dos negociantes locais devido aos frequentes empréstimos concedidos à Real Fazenda (Valim, 2012, p. 57-59).

A resposta de Souza Coutinho procurava contornar os obstáculos apresentador pelo governador. ${ }^{16}$ Com relação à falta de numerário, coerente com análises anteriores, o ministro indicava que a necessidade de moeda devia-se ao aumento das transações econômicas na capitania, perceptível pela elevação das exportações entre 1798 e 1799. Mais adiante ressalta que a falta de numerário era antes sinal de prosperidade do que indício de redução da riqueza. Nesse ponto, Souza Coutinho recusa a ideia de uma drenagem de recursos monetários e metálicos pela metrópole: "essa falta era menos devida a alguns cabedais exportados para Lisboa" (Silva, 2006, v. 2, p. 329). Argutamente, D. Rodrigo indica que a criação da caixa de crédito seria a solução para aquilo que era colocado como problema para o estabelecimento da instituição ao prover um meio de pagamento mais cômodo e igualmente confiável que era o papel-moeda.

Em seu conselho ao governador, D. Rodrigo acrescenta alguns aspectos que não haviam sido assinalados anteriormente. Indica, por exemplo, que o limite de emissão dos bilhetes poderia alcançar até o triplo dos fundos em caixa, talvez o excedesse "uma vez estabelecida a fé e crédito". Ao elencar as vantagens que a caixa de crédito poderia trazer à capitania, D. Rodrigo acrescenta-lhe novas funções. Seriam concedidos empréstimos a lavradores e negociantes, garantidos pelos gêneros a serem exportados e pelo prazo de 6 a 9 meses. Também se daria crédito ao Estado com taxas de juros reduzidas. A caixa poderia realizar o desconto de letras de câmbio ("cambiais") com taxas de juros menores do que as estabelecidas pela lei ou das que eram praticadas na praça de comércio soteropolitana. Entre os

16 Carta régia para D. Fernando José de Portugal, governador da capitania da Bahia, 25 de setembro de 1800 (Silva, 2006, v. 2, p. 326-331). 
direitos da caixa, estava o poder de especular sobre espécies circulantes entre o reino e a Bahia.

No tocante a Pernambuco, a principal instância de articulação foi a Mesa de Inspeção, onde se reuniram seus membros e os negociantes da praça em duas reuniões realizadas em outubro de 1799 para discutirem a proposta da criação da caixa de crédito, bem como uma companhia de seguros, outra dedicada à pesca das baleias e uma terceira voltada à exploração de ferro e cobre. Segundo o desembargador e presidente da Mesa de Inspeção, José Joaquim Nabuco de Araújo, os negociantes, apesar de louvarem as vantagens do projeto ao comércio e à agricultura da capitania, alegaram a falta de moeda circulante para reunirem o capital necessário ao fundo da caixa de crédito. ${ }^{17} \mathrm{Na}$ reunião realizada na instituição em 24 de outubro de 1799, os negociantes da praça diziam: "encontra[r] por principal dificuldade a falta de dinheiro para o mesmo estabelecimento, maiormente depois que com temor dos corsários que têm infestado esta costa tem deixado de continuar as remessas de moeda que eram frequentes da praça do Rio de Janeiro para esta, bem como faziam de Lisboa, Porto, e da praça da Bahia". ${ }^{18}$ Mesmo em um contexto de declínio da produção aurífera, a alegação do corpo mercantil indicava a intensidade da circulação monetária metálica no império, tanto no sentido Brasil-Portugal quanto entre as praças brasileiras, alcançando até mesmo regiões africanas e asiáticas (cf. nota 11).

\section{Considerações finais}

Conforme observado, uma primeira ruptura com o mercantilismo metalista já havia sido realizada ao final do século XVII pela obra de Duarte Ribeiro de Macedo, aspecto aprofundado em escritos posteriores, como

17 Ofício (cópia) do desembargador e presidente da Mesa de Inspeção, José Joaquim Nabuco de Araújo, ao secretário de estado da Marinha e Ultramar, D. Rodrigo de Souza Coutinho. Recife, 10 de novembro de 1799. Arquivo Histórico Ultramarino, Avulsos, Pernambuco, cx. 211, doc. 14350.

18 Termo do acórdão da Mesa da Inspeção de Pernambuco. Olinda, 24 de outubro de 1799. Arquivo Histórico Ultramarino, Avulsos, Pernambuco, cx. 211, doc. 14350. Consta a indicação de dezoito negociantes partícipes da reunião: Alexandre José de Araújo, Antônio Marques da Costa Soares, Bento José da Costa, Domingos Afonso Ferreira, Francisco Carneiro do Rosário, Francisco Xavier Carneiro da Cunha, João da Silva Rego, João do Rego Falcão, Joaquim Pires Ferreira, José da Silva Roque, José de Matos Girão, José Jacques Le Tavoec, José Joaquim Jorge, José Porfírio de Freitas, Lourenço José de Carvalho, Manoel de Matos Simões, Manoel Francisco Maciel Monteiro e Manoel Rodrigues de Aguiar. 
os de Alexandre de Gusmão (1844 [1748]). Partindo do sintoma da perda de metais preciosos, tais autores propõem o fortalecimento da economia portuguesa para sanar os problemas estruturais do desequilíbrio comercial, seja antes ou depois do Tratado de Methuen.

Tal situação agravava-se a olhos vistos com o declínio da produção aurífera brasileira na segunda metade do século XVIII. Em continuidade às medidas pombalinas, a solução preconizada por Souza Coutinho apoiava-se no desdobramento da colônia como um espaço produtivo e consumidor necessário à metrópole.

Contudo, a ênfase no papel-moeda e nas caixas de crédito, pensadas a partir das leituras de Smith e das experiências lombarda e prussiana, como instrumentos de recuperação da economia imperial traria um novo elemento à solução tradicional. A persistência da influência smithiana deve ser aliás ressaltada em meio a escritos dispersos produzidos nas mais diversas conjunturas ao longo de duas décadas.

Se era necessário emitir papel-moeda, no fomento à criação do crédito para a geração da riqueza e no financiamento do Estado, a época de D. Rodrigo também testemunha a descoberta dos tênues limites entre a moeda referida à produção e o símbolo fiduciário, aspecto que indicava que a representação do universo da economia real poderia tornar-se pura representação.

\section{Referências}

AIDAR, Bruno. Uma substituição luminosa: tributação e reforma do Antigo Regime português em D. Rodrigo de Souza Coutinho ao final do século XVIII. Nova Economia, v. 21, p. 137-156, 2011.

ALMODOVAR, António; CARDOSO, José Luís. A History of Portuguese Economic Thought. London; New York: Routledge, 1998. (Routledge History of Economic Thought).

BERDAHL, Robert M. The Politics of the Prussian Nobility: The Development of a Conservative Ideology, 1770-1848. Princeton: Princeton University Press, 1988.

BOYER, Jérôme de. Adam Smith et la théorie quantitative de la monnaie. Cahiers d'économie politique, n. 13, p. 47-71, 1987.

BRASIL. Ministério da Fazenda. Documentos com que instruio o seu relatorio á Assemblea Geral Legislativa do Imperio do Brasil o ministro secretario de Estado dos Negocios da Fazenda, e presidente do Thesouro Nacional, Miguel Calmon du Pin e Almeida, na sessão de 1829... Rio de Janeiro: Na Typographia Imperial e Nacional, 1829.

CAMINHA, Antonio Lourenço (ed.). Obras ineditas de Duarte Ribeiro de Macedo. Lisboa: 
Impressão Regia, 1817.

CARDOSO, José Luís. La monnaie dans la pensée économique portugaise, 1500-1750. In: BLANC, Jérôme; DESMEDT, Ludovic (Dir.). Les Pensées monétaires dans l'histoire. L'Europe, 1517-1776. Paris: Classiques Garnier, 2014. p. 785-807. (Bibliothèque de l'économiste, 7).

CARDOSO, José Luís. Nas malhas do Império: a economia política e a política colonial de D. Rodrigo de Souza Coutinho. In: CARDOSO, José Luís (Org.). A economia política e os dilemas do Império luso-brasileiro (1790-1822). Lisboa: Comissão Nacional para as Comemorações dos Descobrimentos Portugueses, 2001.

CARDOSO, José Luís (ed.). Memórias económicas da Academia Real das Ciências de Lisboa, para o adiantamento da agricultura, das artes, e da indústria em Portugal e suas conquistas (17891815). 3v. Lisboa: Banco de Portugal, 1991. (Obras Clássicas do Pensamento Económico Português, 1).

CARDOSO, José Luís. O pensamento económico em Portugal nos finais do século XVIII, 1780-1808. Lisboa: Editorial Estampa, 1989.

CARDOSO, José Luís. A influência de Adam Smith no pensamento económico português (1776-1811/12). In: CARDOSO, José Luís (Org.). Contribuições para a história do pensamento económico em Portugal. Lisboa: Dom Quixote, 1988. (Universidade Moderna, 84). p. 85-110.

CUNHA, Alexandre Mendes. A Junta da Real Fazenda em Minas Gerais e os projetos de abolição da circulação de ouro em pó (1770-1808): limites às reformas econômicas na colônia dentro da administração fazendária portuguesa. História Econômica \& História de Empresas, v. 15 , n. 2, p. 9-45, 2012.

DIAS, Fernando de Carvalho. Luxo e pragmáticas no pensamento económico do séc. XVIII. Boletim de Ciências Económicas, Faculdade de Direito, Coimbra, v. 5, p. 73-144, 1956.

DUBOEUF, Françoise. Monnaie et banques dans «La richesse des nations ». Revue économique, v. 45, n. 5, p. 1199-1212, 1994.

GHERITY, James A. The Evolution of Adam Smith's Theory of Banking. History of Political Economy, v. 26, n. 3, p. 423-441, 1994.

GUIMARÃES, Carlos Gabriel. O rendimento da capitania do ouro. Revista do Arquivo Público Mineiro, v. 45, n. 1, p. 118-129, 2009.

GUSMÃO, Alexandre de. "Calculo ssobre [sic] a perda do dinheiro do Reino. Offerecido ao Sr. Rei D. João $5^{\circ}$ em 1748". In: Complemento dos ineditos de Alexandre de Gusmão. Porto: Typographia da Revista, 1844. p. 18-23.

HESPANHA, António Manuel. Os poderes do centro: a fazenda. In: MATTOSO, José (Org.). História de Portugal. Lisboa: Estampa, 1993. v. 4: o Antigo Regime (1620-1807), p. 214-236.

LEVY, Fortunée. A circulação fiduciária no Distrito Diamantino. Anais do Museu Histórico Nacional, Rio de Janeiro, v. 2, p. 269-280, 1941.

LIMA, Fernando Carlos Greenhalgh de Cerqueira. A lei de cunhagem de 4 de agosto de 1688 e a emissão de moeda provincial no Brasil (1695-1702): um episódio da história monetária do Brasil. Revista de Economia Contemporânea, v. 9, p. 385-410, 2005.

MADUREIRA, Nuno Luís. Crédito e mercados financeiros em Lisboa. Ler História, n. 26, p. 21-44, 1994. 
MAGALHÃES, Joaquim Romero. Labirintos brasileiros. São Paulo: Alameda, 2011.

MAGALHÃES, José Calvet de. História do pensamento económico em Portugal. Capítulo III. Boletim de Ciências Económicas, Faculdade de Direito, Coimbra, v. 9, p. 65-179, 1965-1966.

MAGALHÃES, José Calvet de. História do pensamento económico em Portugal. Capítulo III (cont.). Boletim de Ciências Económicas, Faculdade de Direito, Coimbra, v. 10, p. 63-165, 1967.

MAGALHÃES, José Calvet de. História do pensamento económico em Portugal. Capítulo III (cont.). Boletim de Ciências Económicas, Faculdade de Direito, Coimbra, v. 11, p. 1-73, 1968.

NOVAIS, Fernando A. Portugal e Brasil na crise do Antigo Sistema Colonial (1777-1808). 5. ed. São Paulo: Hucitec, 1989.

Ofício (cópia) do desembargador e presidente da Mesa de Inspeção, José Joaquim Nabuco de Araújo, ao secretário de estado da Marinha e Ultramar, D. Rodrigo de Souza Coutinho. Recife, 10 de novembro de 1799. Arquivo Histórico Ultramarino, Avulsos, Pernambuco, cx. 211, doc. 14350 .

PEDREIRA, Jorge Miguel (ed.). José Joaquim da Cunha de Azeredo Coutinho. Ensaio económico sobre o comércio de Portugal e suas colónias. Lisboa: Banco de Portugal, 1992. (Obras Clássicas do Pensamento Económico Português, 3).

PUNTONI, Pedro. O "Mal do Estado Brasílico": a Bahia na crise final do século XVII. In: CARRARA, Angelo; SÁNCHEZ SANTIRÓ, Ernest (coords.). Guerra e fiscalidade na Ibero-América colonial (séculos XVII-XIX). Juiz de Fora; México DF: Ed. UFJF; Instituto Mora, 2012. p. 265-299.

RIST, Charles. History of Monetary and Credit Theory from John Law to the Present Day. New York: Augustus M. Kelley, 1966. (1. ed. ing., 1940).

SANTOS, Nívia Pombo Cirne dos. O Palácio de Queluz e o mundo ultramarino: circuitos ilustrados (Portugal, Brasil e Angola, 1796-1803). Tese (Doutorado em História Social) - Instituto de Ciências Humanas e Filosofia, Universidade Federal Fluminense, Niterói, 2013.

SERRÃO, José Vicente (ed.). Domingos Vandelli. Aritmética política, economia e finanças. Lisboa: Banco de Portugal, 1994. (Obras Clássicas do Pensamento Económico Português, 8).

SILVA, Ana Rosa Cloclet da. Inventando a Nação: intelectuais ilustrados e estadistas luso-brasileiros na crise do Antigo Regime português (1750-1822). São Paulo: Hucitec; Fapesp, 2006.

SILVA, Andrée Mansuy-Diniz. Portrait d'un homme d'État: D. Rodrigo de Souza Coutinho, Comte de Linhares, 1755-1812. Paris: Fundação Calouste Gulbekian, 2002-2006. 2v.

SILVA, Andrée Mansuy Diniz (ed.). D. Rodrigo de Souza Coutinho. Textos políticos, económicos e financeiros (1783-1811). 2v. Lisboa: Banco de Portugal, 1993. (Obras Clássicas do Pensamento Económico Português, 7).

SMITH, Adam. A riqueza das nações. Investigação sobre sua natureza e suas causas. 2 v. Tradução de Luiz João Baraúna. São Paulo: Nova Cultural, 1996. (Os Economistas).

SOMBRA, Severino. História monetária do Brasil colonial. Rio de Janeiro: Almanak Laemmert, 1938.

SOUSA, Rita Martins de. Moeda e metais preciosos no Portugal setecentista, 1688-1797. Lisboa: Imprensa Nacional, Casa da Moeda, 2006. (Temas portugueses). 
SOUZA, Laura de Mello e. Desclassificados do ouro: a pobreza mineira no século XVIII. 4. ed. Rio de Janeiro: Graal, 2004.

STEUART, James. An Inquiry into the Principles of Political Oeconomy... 2v. London: A. Millar and T. Cadell, 1767.

STORRS, Christopher. The Savoyard Fiscal-Military State in the Long Eighteenth Century. In: STORRS, Christopher (ed.). The Fiscal-Military State in Eighteenth-Century Europe: Essays in honour of P. G. M. Dickson. Surrey: Ashgate, 2013. p. 201-235.

Termo do acórdão da Mesa da Inspeção de Pernambuco. Olinda, 24 de outubro de 1799. Arquivo Histórico Ultramarino, Avulsos, Pernambuco, cx. 211, doc. 14350.

VALIM, Patrícia. Corporação dos enteados: tensão, constestação e negociação política na Conjuração Baiana de 1798. Tese (Doutorado em História Econômica) - Faculdade de Filosofia, Letras e Ciências Humanas, Universidade de São Paulo, São Paulo, 2012.

\section{Sobre o autor}

Bruno Aidar - profbrunoaidar@gmail.com

Universidade Federal de Alfenas, Alfenas, Minas Gerais, Brasil.

ORCID: https://orcid.org/0000-0003-1225-9469.

\section{Sobre 0 artigo}

Recebido em 08 de dezembro de 2016. Aprovado em 01 de março de 2017. 